\title{
LAS CIENCIAS DE LAS POLÍTICAS Y EL CONTROL COMO REQUISITO
}

\author{
NECESARIO DE LA DEMOCRACIA
}

\section{HÉCTOR J. ZIMERMAN}

\section{UNIVERSIDAD NACIONAL DEL NORDESTE}

Profesor Titular de Derecho Político. Master en Relaciones Internacionales (UB), Magister en Metodología de la Investigación (UNNE). Magister en Procesos de Integración Regional (UNNE), Doctor en Derecho (UNNE). Ex-Decano y Vicerrector de la Universidad Nacional del Nordeste. Fundador de la Asociación Argentina de Derecho Político (Presidente M.C.).

\section{RESUMEN}

El presente trabajo desarrolla la evolución de la política científica como parte de los saberes disciplinares académicos. Siendo la Ciencia Política una ciencia novel, se desentraña lo que por etapas se ha descripto como su objeto de estudio, comenzando por la teoría del gobierno hasta alcanzar en la actualidad el dominio de las ciencias políticas y el estado de las políticas públicas. A la par se observan criterios respecto de la democratización, la responsabilidad en la gestión pública y la teoría del control tanto horizontal como vertical.

\section{AbSTRACT}

This paper develops the evolution of science policy as part of the academic disciplinary knowledge. Political Science being one novel science unravels staged what 


\section{LAS CIENCIAS DE LAS POLÍTICAS Y EL CONTROL \\ COMO REQUISITO NECESARIO DE LA DEMOCRACIA}

has been described as its object of study, beginning with the theory of government to achieve mastery of political science and public policy status today. At the same approaches to democratization, responsibility in the public management and the theory of both horizontal and vertical control are observed.

\section{De la POLÍtica CiENTífiCa a las CienCias POLíticas.}

La política, devenida en Ciencia Política, es, relativamente una ciencia novedosa en razón de su tardía aparición como disciplina incorporada a los estudios curriculares en los ámbitos académicos desarrollados. Se estima que en una disputa temporal, tanto en Europa como en Estados Unidos, recién a mediados del Siglo XIX se incorporan en las Universidades los estudios relativos a "lo político", identificándose con distintos nombres su objeto primario ${ }^{1}$.

La posibilidad de abordar los estudios de la política no debe ser desmerecidos en virtud de este reconocimiento postmoderno. La política como parte de los estudios del gobierno o los gobiernos en realidad, comienzan entrecruzados con la moral y la filosofía en la antigua Grecia, siendo posiblemente Platón quien los aborda de manera sistemática y estructurada, siendo Aristóteles quien originalmente ubica a la política en el cuadro de las ciencias ${ }^{2}$.

La delimitación del objeto de estudio ha implicado también la mutación de la centralización del marco disciplinario. Esta temprana identificación en la práctica como un acercamiento al "arte del buen gobierno", al provenir de la identificación del Estado

\footnotetext{
${ }^{1}$ En Europa la disciplina tomó auge como parte de los estudios de la Teoría del Estado -a secas-, mientras que en Estados Unidos regularmente los tratadistas han referido a la Teoría del Gobierno.

${ }^{2}$ Las obras más reconocidas de estos filósofos griegos respecto de los estudios políticos son "La República” y "La Política” respectivamente.
} 
Moderno con el nacimiento de la burocracia estatal, la separación de la confusión del patrimonio público y privado del gobernante, y la distinción del Estado como una delimitación territorial en base a lo jurídico ${ }^{3}$, separando a su vez la Teoría y el Derecho Constitucional con una visión estática, frente a la Ciencia Política acaparada como una suerte de conocimiento empírico poniendo en jaque el principio de la división de poderes, y el sistema de checks and balances (popularizado erróneamente como "frenos y contrapesos"), aludiendo específicamente al control interorgánico de manera primigenia, tanto en Estados Unidos como en Europa.

Posar la mirada sobre la actividad del Estado llevó a consagrar una noción verticalista, privilegiando el conocimiento de las agencias burocráticas, desconociendo en gran medida la aceptación o rechazo de la ciudadanía, y eliminando en la práctica el control y el consenso de abajo hacia arriba. En síntesis, una conjugación más bien de poderío en un sentido cuasi-exclusivo unilineal.

El nacimiento de los partidos políticos, dándoles una protección legal al consagrarlos como organizaciones reconocidas como permanentes y monopolizadoras de las candidaturas a los cargos públicos, las convirtió en "maquinarias electorales" que en principio ataban la cohesión ciudadana a programas ideológicos -en un extremohasta conformar entidades "catch all" -en el otro- ${ }^{4}$.

${ }^{3}$ Esto conlleva a la creación de la ley, su aplicación administrativa, y su interpretación y ejecución, en un mismo tiempo y marco normativo.

\footnotetext{
${ }^{4}$ La denominación "catch all", se puede traducir como "partido atrapalotodo", ya que su interés se basa en conseguir la mayor cantidad de adhesiones en un período eleccionario, sin privilegiar la ideología de los adherentes. No hay acuerdo entre los autores en lo relativo a la fecha de su aparición. Mientras los norteamericanos aluden a partidos de la segunda posguerra, en América se puede identificar al Peronismo en Argentina, o los Partidos mayoritarios en Uruguay, con anterioridad.
} 


\section{LAS CIENCIAS DE LAS POLÍTICAS Y EL CONTROL COMO REQUISITO NECESARIO DE LA DEMOCRACIA}

También la expansión del voto reconocido como categoría "universal", colaboró enlazando Estado y Sociedad. A la par de reconocer la existencia de grupos influyentes, que cuando cohesionan sobre intereses organizados, pasan de ser grupos de interés a grupos de presión. Estos estudios en base a cuestiones referentes a la legitimidad, ampliaron la base de toma de decisiones tanto por parte de los gobiernos como del electorado. En los sistemas democráticos sin el consenso ciudadano tanto la sustentabilidad como la gobernabilidad, resultan imposibles a mediano o largo plazo ${ }^{5}$.

Este nuevo criterio, desplazó la unidad de análisis inicial, pasando del Estado a los estudios sobre El Poder. Esto también provocó el aumento de la influencia de los cientistas de cuño sociológico, donde en determinadas áreas se entremezclan la Sociología y la Política, derivando incluso en Sociología Política, destacándose en Francia, entre otros, Prelot y Duverger, o en E.E.U.U., Merton, Parson, Laswelle Easton, sin desmerecer a científicos restantes. La expresión Sociológica Política no debe entenderse como un híbrido, sino más bien como una etapa importante en el desarrollo de las Ciencias Sociales donde las "actitudes" de la población, y las "aptitudes" de los gobernantes, orientan y demarcan la toma de decisiones y el uso del poder coactivo para tornar obligatorias las soluciones adoptadas.

\footnotetext{
5 Autores como Duverger, distinguen entre los partidos políticos y los grupos de presión, en base a la temporalidad. Mientras los primeros son propios del Siglo XX, los segundos se encuentran en todas las épocas.
} 
Los estudios pioneros de estos reconocidos sociólogos permiten enlazar la noción de poder político con poder estatal y electorado. Así comentan Abal Medina (h) y Nejamkins ${ }^{6}$ :

“El poder político está asociado a la "utilidad de una regulación centralizada y territorial", es por ello que se asocia poder político a poder estatal.

Nosotros a este concepto optamos por definirlo como las variables políticoinstitucionales que hacen referencia a las reglas de diversos tipos que determinan una estructura diferencial de probabilidades para la realización de los intereses o metas de los distintos grupos sociales. En este sentido, sin lugar a dudas que el Estado en tanto autoridad centralizada con capacidad distintiva para generar reglas cumple un rol central. Sin embargo, no es correcto dejar de lado la influencia netamente política que tienen determinados actores, tales como partidos o movimientos, tienen en las sociedades aún sin ocupar lugares en el aparato estatal.

El poder militar está vinculado al uso y organización de la fuerza física. Si bien en determinado momento histórico este tipo de fuente de poder ha tenido niveles importantes de autonomía, también es cierto que en función de los estados modernos puede ser entendido como una de las diferentes facetas del poder político, restringidas en su uso por variables tanto económicas como ideológicas.

Por último, cuando nos referimos al poder ideológico, entendemos que este procede de "la necesidad humana de dotar a la vida un significado último, compartir normas y valores, y participar en prácticas estéticas y rituales.”. Los elementos asociados a este poder constituyen algo así como "El mapa cognitivo desde el que los

\footnotetext{
${ }^{6}$ La referencia se encuentra en el texto "La política en conflicto. Reflexiones en torno a la vida pública y la ciudadanía", trabajo que compendia artículos de varios autores argentinos.
} 


\section{LAS CIENCIAS DE LAS POLÍTICAS Y EL CONTROL COMO REQUISITO NECESARIO DE LA DEMOCRACIA}

actores interpretan su mundo". Es importante señalar que este tipo de poder se puede expresar en una religión, tal cual ocurrió en la antigüedad, o en algunos de los relatos característicos de la modernidad tal el caso del marxismo o del liberalismo".

El avance del análisis sistémico, cuyo nacimiento se presume en la antropología, interpretó tendencias como el hiperfactualismo, el conductalismo, e incrementalismo, y algunos "ismos" mas, para caer en el análisis de sistemas y teoría del sistema político, y donde quien más desarrollara esta corriente fuera David Easton ${ }^{7}$, y retomar así la discusión sobre un nuevo abordaje de la política y caer en otro desplazamiento de lo que tradicionalmente se llamaría "objeto de estudio" de la posguerra. Esto daría lugar asimismo, posteriormente a un área dentro de las ciencias políticas, asumida como "la política comparada", profundizada en parte como "sistemas políticos comparados" y donde, en vez de enfrentarse, se complementan saberes disciplinarios del Derecho Constitucional, la Historia, la Ciencia Política, la Sociología, y las Relaciones Internacionales.

En principio la ventaja de este nuevo tipo de abordaje es el corrimiento de factores claves en el Siglo XX, especialmente la ideología, privilegiando el proceso de toma de decisiones y el resultado fáctico de la política. En esta postura, se prioriza la discusión sobre quien es "el artífice" del "reparto autoritativo de bienes y valores", abarcando nociones esenciales como la legitimidad de los actores (principio de cualidad), y la concepción de "overload” o sobrecarga, (relacionando la cuantificación de demandas), con la posibilidad de caer en tensiones dentro del sistema, con la

\footnotetext{
${ }^{7}$ Easton parece trabajar sobre la noción de fusión entre el objeto y el método de abordaje del campo disciplinar. En la práctica esto implicaría la delimitación del objeto y el método de abordaje de manera conjunta.
} 
necesidad de corregir las mismas para lograr la "gobernanza" necesaria. Easton observa en "Política Moderna: un estudio sobre la situación de la ciencia política":

"La ciencia política se ve obligada a extraer del sistema social general algunos elementos variables que parecen más íntimamente unidos que otros, tal como en la economía sucede con el precio, la oferta, la demanda y la selección de las necesidades. El considerar estos elementos como un subsistema que puede ser temporalmente con éxito, en forma separada de todo el sistema social, es otra de las tareas de la ciencia política. El instrumento analítico o mental para este objeto es el sistema teórico. Consiste, primeramente, en un conjunto de conceptos que corresponden a los factores variables de la política que son de importancia. En segundo lugar, consiste en las declaraciones sobre las relaciones que hay entre estos conceptos. La teoría sistémica corresponde, en el nivel del pensamiento al concreto sistema político empírico de la vida diaria".

La posibilidad de aislar el subsistema político dentro del sistema societal (en palabras de Easton), no solo mejora el conocimiento de cada sistema político en particular de acuerdo a las circunstancias, sino que se llegaría mas allá comparando los sistemas políticos particulares entre sí, obteniendo conclusiones que relacionan los niveles teóricos con la empiria. Así:

"Podíamos haber empezado con la hipótesis que en la existencia misma de un sistema político exige que se satisfagan ciertas necesidades o funciones básicas. $\mathrm{Si}$ hubiésemos podido identificar estas funciones, habríamos procedido a entonces a discutir los diversos patrones entonces a discutir los diversos patrones regularizadores de la actividad que han surgido en todo tiempo y lugar, como mecanismos para realizar estas tareas". 


\section{LAS CIENCIAS DE LAS POLÍTICAS Y EL CONTROL \\ COMO REQUISITO NECESARIO DE LA DEMOCRACIA}

En consecuencia:

"Si se descubrieran tareas idénticas o similares en todo sistema político, contemporáneo o histórico, sería posible examinar comparativamente la forma en que estas instituciones cumplen las mismas tareas bajo las condiciones diferentes de cada sistema político. La ciencia política estaría en condiciones de establecer mas allá de la experiencia de un solo sistema político o de los sistemas de una sola cultura o civilización".

El aporte de Easton significará la posibilidad de pasar de un nivel descriptivo a un nivel comparativo. Como corolario, se podrían comparar los mismos sistemas políticos en épocas diferentes, señalando los factores determinantes del cambio político. En esta vía Ciancino ${ }^{8}$ acomete y traspasa algunos límites tradicionales de la disciplina:

"Tanto la génesis larga como la génesis corta, con los cambios y/o alteraciones que han señalado en la institucionalidad de los regímenes políticos, sobre todo en aquellos de democratización reciente, son indispensables para entender en modo integral las principales dimensiones de inteligibilidad y análisis de la calidad de las democracias. El tema por si mismo resulta necesario porque puede permitirnos discutir seriamente o no sobre la pertinencia o no de los tradicionales instrumentos y criterios analíticos con los cuales contamos para examinar algunas de las múltiples dimensiones que el régimen particularmente en aquellos aspectos que puedan referir a la "buena" o "mala" salud de las instituciones políticas. De igual modo, nos ayuda a la introducción de criterios más reales (y por ende con un grado de confiabilidad en el tema de los

\footnotetext{
${ }^{8}$ En un sugestivo ensayo, este autor vaticina "La muerte de la ciencia política", acusando a la disciplina de "su obsesión metodológica, de las presunciones de su ideología cientificista, de su imposible aspiración a la neutralidad valorativa, de su débil sensibilidad la historia y el cambio social".
} 
indicadores) para observar el grado de consolidación democrática y de aseguramiento de derechos (que es el último puerto hacia el cual se quiere dirigir precisamente el análisis de la calidad de la democracia).”

Como conclusiones de la relevancia del análisis sistémico, como escalón relevante del análisis sistémico hacia las ciencias de las políticas, podríamos señalar las que se detallan seguidamente a continuación:

a) En la década de los sesenta, la revisión de los sistemas políticos demostraron que a dicotomía Autoritarismo vs. Democracia, no aportaba mayores categorizaciones ya que el debate se daba tanto en el plano interno como en el escenario internacional.

b) El proceso de retroalimentación dentro de un sistema político revelaba diferencias enormes en el plano del proceso de la toma de decisiones respecto de la información necesario y suficiente para la hechura de las políticas, en consideración a estudiar regímenes "abiertos" en contraposición a los denominados "cerrados".

c) El análisis ha variado el enfoque clásico de la pertinencia de contar un sistema con un régimen de división de poderes, que no necesariamente conducen a la gobernabilidad y la estabilidad en base a los requisitos propios de las democracias.

d) El análisis comparado ha consagrado en el tiempo (especialmente mitad del siglo XX en adelante), una percepción mucho más favorable en beneficio de los sistemas parlamentarios frente a los presidencialistas. 


\section{CIENCIA POLÍTICA, DEMOCRACIA Y BIENESTAR, COMO PARTE INICIAL DE LA PUBLIC} POLICY CONTEMPORÁNEA

Lindblom es uno de quienes se ha preocupado por destacar la necesidad de repensar la economía como ingrediente sustancial de la democracia como forma de gobierno responsiva. Incluso el impulso dado al Welfarstate, prácticamente eliminó todo retroceso a la no proliferación del estado-centrista, hasta la caída del Estado de Bienestar. Un escalón relevante en el ascenso de la concepción de las ciencias políticas, ha sido la combinación entre ciencia política, economía, administración, y psicología. Aunque Laswell dará inicio a la Contemporary Public Policy, y el estudio sobre The Policy Makers, las reflexiones del autor que citamos al comienzo del párrafo funcionan como de extremada significación. Este comentario, alude a una significación especial, atento a que Lindblom, ya en la década del 20, dará un impulso a la ciencia política en Estados Unidos y se convertirá en el formador de los cientistas que hacen pie en los estudios de política y administración pública con orientación hacia las políticas públicas en base a autores como John Dewey y Charles Merriam ${ }^{9}$.

El aporte de Lindblom emerge como un balance en la acción social racional en el sector político económico. Explica que:

“El logro de una organización político-económica racional por parte de una nación depende no sólo de las técnicas económicas particulares que emplee, sino también del grado de información política y económica de sus ciudadanos, de sus convicciones y actitudes - de hecho, del conjunto de su cultura-, así como de circunstancias fortuitas.

\footnotetext{
${ }^{9}$ Según Douglas Torgerson, Lindblom, (junto a Lasswell y Herbert Simon), particulariza el esfuerzo de orientar las políticas públicas desafiando la visión tecnocrática.
} 
Por lo tanto, nadie puede llegar a saber si una nación logrará realizar una acción social racional excepto cuando su procesos y técnicas sociales puedan medirse respecto de los prerrequisitos de la acción social racional".

En el análisis necesario que entiende Lindblom se debe efectuar en toda planificación "como intento de acción calculada racionalmente para lograr un fin", se encuentran:

a) Los fines, metas o valores, ya que mediante los mismos se puede apreciar la acción social en el sector político-económico.

b) El cálculo y el control como procesos gemelos, lo que requiere un cálculo tanto racional como efectivo. Para refinar la praxis se mesura la contribución reciente de la sociología, la antropología y la psicología.

c) El proceso social de la economización es cálculo y control respecto de la utilización del trabajo y de otros recursos en la producción.

d) Reconocimiento de cuatro procesos sociopolíticos centrales, en especial: 1) El sistema de precios como mecanismo de control y cálculo, 2) La jerarquía como proceso donde los líderes controlan a los no líderes, 3) La poliarquía donde los no líderes controlan a los líderes (proceso llamado regularmente democracia), y 4) La negociación como proceso por el cual los líderes se controlan entre sí.

Una distinción que marcará este autor acerca del sistema de la elección y la adjudicación es que en tiempos de guerra se confirman las deficiencias del sistema de precios que normalmente se elabora en épocas de paz y aclara:

“Sin embargo, la economización en época de guerra no debe alentar a fáciles generalizaciones acerca de las posibilidades de prescindir del sistema de precios en época de paz. En efecto, para repetir un punto que hemos señalado a menudo, lo que 


\section{LAS CIENCIAS DE LAS POLÍTICAS Y EL CONTROL COMO REQUISITO NECESARIO DE LA DEMOCRACIA}

permite el desplazamiento del sistema de precios es, sobre todo, la subordinación de la soberanía del consumidor al control del liderazgo. Esta subordinación es más limitada en época de paz que en época de guerra.”.

Justamente el desplazamiento del objeto de estudio en el período de entreguerras hacia el fenómeno del Poder, es lo que incidirá durante la Segunda Guerra y la posguerra, para trabajar el análisis sistémico y las políticas públicas.

La incidencia de Laswell proviene del reconocimiento de ahondar el fenómeno de las políticas públicas, comprendiendo con ellas, las acciones y procesos que se efectivizan desde el sector público con el propósito de paliar, enmendar o suplir una carencia que abarca a una porción importante de la población y, que ella misma, ya sea en forma individual o conjunta, no se encuentra en condiciones de realizar.

El análisis de políticas públicas según Laswell surge como un programa de investigación denominado Policy Science y trata sobre "el conocimiento del proceso de la política y en el proceso de la política", articulando ciencia y gobierno en un marco democrático. "Su propuesta resulta de una historia intelectual, del desarrollo científico de una nación”. El problema entre el saber y el poder, entre la ciencia y el Estado, resulta en "la cuestión concreta acerca de la relación entre el conocimiento natural y social que una sociedad posee en su comunidad intelectual y las decisiones que los gobernantes y legisladores democráticos afrontan".

Lo que importa es preguntarse hasta donde las decisiones políticas administrativas pueden prescindir del conocimiento científico en las sociedades cuya producción, comunicación, prosperidad y desarrollo, descansan en la ciencia, la tecnología y la información. . En un doble sentido las ciencias sociales manifiestan un interés creciente por el proceso decisorio de la política como objeto significativo de 
estudio y poseen una capacidad creciente para perfeccionar la racionalidad del proceso decisorio de la política. Tienen interés y capacidad intelectual.

Laswell define a las ciencias de las políticas como el conjunto de disciplinas que se ocupan de explicar los procesos de elaboración y ejecución de las políticas, de la recopilación de datos y de la producción de interpretaciones relevantes para los problemas de políticas en un período determinado. Las policy sciences tienen un compromiso valorativo fundamental con la idea liberal libertaria de la política y la democracia. Estas nuevas ciencias seleccionan sus objetos de estudio desde posiciones valorativas previas, solo escogen los problemas básicos para la dignidad humana y sus políticas respectivas.

Un hecho calificado como problema es resultado de una cadena causal compleja de factores sociales y también resultado de la evolución de las percepciones y valoraciones de una sociedad. De allí la exigencia "del esclarecimiento de las metas y de los propósitos valorativos que subyacen en una política”.

"Las ciencias de las políticas tienen dos marcos de referencia separables pero entrelazados; el conocimiento del proceso de la política y el conocimiento en el proceso de la política. Knowledge of alude a la tarea de conocer el proceso de decisión de la política. En el área de los politólogos lo que interesa es describir procesos y sucesos, y tal vez explicarlos. Knowlodge in significa la tarea de incorporar los datos y los teoremas de las ciencias en el proceso de deliberación y decisión de los políticos con el propósito de corregir y mejorar la decisión pública. Es una empresa de teoría normativa, que conforme a los enunciados causales de las ciencias, indica cuales son los cursos de acción idóneos y eficaces y eficientes para poder realizar los fines preferidos en 


\section{LAS CIENCIAS DE LAS POLÍTICAS Y EL CONTROL \\ COMO REQUISITO NECESARIO DE LA DEMOCRACIA}

contextos dados y restrictivos. Es una teoría que pretende definir los mejores instrumentos y procedimientos de la acción pública.”.

La originalidad de Laswell radica en varios puntos. El primero de ellos es que surgió como un programa de investigación "El conocimiento del proceso de la política y en el proceso de la política", en los años de la guerra fría con la pretensión de reafirmar el liberalismo, la democracia, el libre mercado, y los valores de la dignidad humana. El hincapié respecto de la democracia aquí tiene una doble validez, hacer pie frente a la amenaza del comunismo, analizar la public policy en los sistemas donde el control se torna absolutamente necesario, especialmente por el principio de legitimidad y la relevancia de la accountability. En palabras de Aguilar Villanueva ${ }^{10}$ :

"La polarizada situación internacional planteaba entonces de "como utilizar nuestros recursos con la más sabia economía", "como aumentar la función inteligencia para aumentar la racionalidad de la política", "como lograr que los hechos y las interpretaciones influyan efectivamente en el proceso de toma de decisiones".

La experiencia consistió en la participación de sociólogos, politólogos, psicólogos sociales, antropólogos, en la Biblioteca del Congreso, bajo la dirección de Laswell en la "División Experimental para el Estudio de las Comunicaciones en Tiempos de Guerra", y sería el puntapié inicial para lo que el director llamaría en 1951 Policy Sciences. Esta citada experiencia sentó las bases para lo que se denominó "la batalla ganada del método" en base a la primacía del pragmatismo y el positivismo, utilizando el método cuantitativo, y un interés especial de posar la mirada en una mixtura entre la economía y la psicología. Siendo la base un programa multi -

\footnotetext{
${ }^{10}$ Este autor es uno de los más reconocidos en habla hispana en estudios relativos a las Políticas Públicas.
} 
interdisciplinario de investigación centrado en la hechura de las políticas, en un artículo fundador que visualiza la orientación que demuestran las diversas ciencias sociales hacia las políticas.

Lo que se discutirá a partir de aquí es que tanto la implementación como la evaluación necesitan de la mayor cantidad de recursos técnicos-científicos, independientemente de la intuición o popularidad de los gobernantes de turno.

\section{LA CAÍDA DEL ESTADO DE BIENESTAR Y EL PASO A LA DEMOCRACIA DELEGATIVA}

Dentro de los modelos clásicos de las relaciones Estado-Sociedad, en los países latinoamericanos, y particularmente en el nuestro, se han reconocido tres vertientes, 1) El modelo agroexportador de cuño liberal, 2) El Estado de Bienestar con respaldo en el constitucionalismo social, y 3) El Estado neo-liberal, partidario de la Reforma estatal y el combate a la crisis fiscal.

A la par de la caída del Estado de Bienestar producto del agotamiento del modelo I.S.I., Industrialización para sustitución de importaciones, en la década del 70 irrumpieron los regímenes autoritarios, profundizados por el ascenso de los militares en el ejercicio del poder, o regímenes dictatoriales personalistas. La imposibilidad de paliar las crisis y generar modelos alternativos al descenso del WelfareState, trajo lo que Huntington ha llamado la "Tercer Ola de Democratización", casi en continuum a los estudios de Linz analizando con anterioridad el "Quiebre de las Democracias". El planteamiento del cientista Guillermo O’Donnell, generó un nuevo paradigma, el de la democracia delegativa, refiriéndose con cierta inclinación a sustituir como forma de 


\section{LAS CIENCIAS DE LAS POLÍTICAS Y EL CONTROL COMO REQUISITO NECESARIO DE LA DEMOCRACIA}

gobierno a la tradicional democracia reemplazada por la "poliarquía", reconociendo así un sistema de mayor amplitud e inclusión ${ }^{11}$.

La desventaja de la denominada democracia delegativa, es que en este sistema de poliarquía, los requisitos de democracia formal se cumplen periódicamente, pero la democracia material no se trasunta en el resguardo efectivo y concreto de los principios de igualdad y libertad. No hay discusión posible en alusión a la concurrencia de la libre competencia electoral de los partidos políticos, libertad de prensa, inexistencia defraude o proscripciones, no interrupción de los mandatos por causas ilegales, traspaso del gobierno a partidos o alianzas de distinto cuño ideológico, etc.. Donde si se encuentra un déficit extremadamente visible es en el principio de accountability, tanto en sentido horizontal como vertical. Como este principio alude a la denominada "rendición de cuentas en la "res pública"”, el control en ambos sentidos se torna deficiente y en ocasiones inexistente, lo que afecta en demasía la calidad institucional, considerando la perfomance de la gestión pública.

El mismo Laswell reitera que solo se puede hablar de políticas públicas en sistemasdemocráticos, en base a que en los regímenes autocráticos el posicionamiento del electorado es más bien de asentimiento que de debate o labor conjunta con el poder. La imposibilidad de controlar no solo atenta contra lo que denominamos calidad institucional sino que apareja casi imposible algún tipo de control interorgánico o ciudadano. Incluso las reformas constitucionales que han proliferado en la era de latransición democrática en Latinoamérica, no necesariamente han obtenido un mejor desempeño en las instituciones de gobierno. A la par la invasión neo-liberal de fin de

\footnotetext{
${ }^{11}$ O’Donnell también ha sido reconocido como el autor del paradigma del Estado Burocrático Autoritario.
} 
siglo XX, no produjo los resultados prometidos sino que ahondó la brecha entre los que mas tienen frente el resto, y operó como freno a la movilización social en los Estados donde la clase media se había constituido históricamente como el motor del crecimiento económico y de la capacidad de consumo per cápita, en desmedro también de los servicios básicos y las prestaciones en salud y educación.

Para O’Donnell, las democracias delegativas no necesariamente son representativas en el cabal sentido del término. Su caracterización se conforma por lo siguiente:

a) Se basan en la premisa de que la persona que gana la elección presidencial está autorizada a gobernar como el o ella crea conveniente, con la restricción de la normativa constitucional o el término de su mandato.

b) Los presidentes se ven por encima de los partidos políticos y de los intereses organizados.

c) No es ajena a la tradición democrática, se basan en el principio de una mayoría legitimada, pero una vez electos, los gobernantes esperan que los votantes se conviertan en una audiencia pasiva pero complaciente.

d) El líder es un guía que busca un todo armonioso y con el colaboran los "técnicos", que deben ser protegidos por la Presidencia frente a la resistencia de la sociedad.

e) La representación implica accountability. En las democracias institucionalizadas la accountabilityeige rendición de cuentas vertical (frente a la sociedad) y horizontal (interorgánica). Esto es ajeno al accionar en la democracia delegativa.

f) Aunque tengan elementos que pueden ser similares a los concurrentes en regímenes autoritarios, no dejan de ser poliarquías. 


\section{LAS CIENCIAS DE LAS POLÍTICAS Y EL CONTROL COMO REQUISITO NECESARIO DE LA DEMOCRACIA}

O’Donnell también coincide en que otros autores exigen para la consolidación democrática un alto grado de institucionalización. Para entender esto se separa la permanencia democrática en el tiempo de su calidad y el desempeño de las instituciones políticas. Esta comparación trata a su vez del reconocimiento de reglas formales e informales. Las primeras obedecen a la Constitución, la legislación derivada, y su reglamentación. Esto requiere una adecuación del comportamiento ciudadano a las reglas formales. La paradoja se da que ante la falta de adecuación requerida, esto no implica desobediencia a reglas, sino más bien lo contrario. En las democracias no consolidadas la obediencia a reglas informales se encuentra altamente institucionalizada. "El problema es que concentrar la atención en las instituciones formales y organizacionalmente materializadas de la poliarquía nos impide ver otra institución, informal y en ocasiones encubierta, que tiene enorme influencia en muchas nuevas poliarquías: el clientelismo, y más generalmente el particularismo”.

\section{LA EXIGENCIA DEL CONTROL PARA LA CONSOLIDACIÓN DEMOCRÁTICA}

La relación del desempeño institucional y la accountability es de carácter directa. Justamente uno de los débitos, a la par que desafío, los escritos sobre la calidad institucional se han incrementado copiosamente $y$, en consecuencia, depende proporcionalmente de la capacidad responsiva de las instituciones públicas en la hechura y eficacia de las políticas públicas.

Para Bresser Pereyra ${ }^{12}$, la consolidación democrática ha permitido el nacimiento de un nuevo Estado, donde:

12 Posiblemente Luiz Carlos Bresser Pereyra, junto a Bernardo Klisberg, sean los cientistas más influyentes en esta última etapa, correspondiente al primer decenio del Siglo XXI, dentro de las 
"Las tres instancias políticas que actúan en las modernas sociedades capitalistas -La sociedad civil, el Estado (organizaciones e instituciones) y el gobierno- deben asumir nuevas formas, nuevos roles, nuevas maneras de relacionarse entre sí, y de esta manera dar origen a un nuevo tipo de ejercicio democrático del poder”.

Las proposiciones de este último autor son tres:

1) El Estado capitalista de fin de siglo $X X$, para ser más competitivo con las exigencias tanto económicas como de eficiencia, debe ser reformado, buscando más autonomía en lo administrativo y responsabilidad en lo político,

2) Después de la exigencia económica se requiere que la opción democrática (o poliárquica) tenga prioridad sobre la precitada.

3) El requerimiento de una organización estatal más eficiente y de un sistema político más democrático tanto exógeno como endógeno.

De la manera planteada, los derechos ciudadanos serán cubiertos en lo civil, cuando las instituciones los garanticen, en lo social, cuando la recaudación tributaria asegure la salud, la educación, y un ingreso mínimo universal, en lo político, cuando las Instituciones del Estado consigan un gobierno más representativo, más participativo y más responsable.

Las reflexiones de este autor también apuntan a conciliar las virtudes del republicanismo con la labor cotidiana del funcionariado público y del contralor ciudadano, como ingredientes básicos de la democratización. Así se reseña que: 


\section{LAS CIENCIAS DE LAS POLÍTICAS Y EL CONTROL COMO REQUISITO NECESARIO DE LA DEMOCRACIA}

"El moderno republicanismo asume el imperio de la ley, y es consciente de cuán importantes son las instituciones y los sistemas de incentivos, pero también es consciente de sus limitaciones. Y es por esta razón que los nuevos republicanistas plantean la necesidad de que existan funcionarios dotados de valores cívicos que estén comprometidos con el interés público. Al hacer esto, el republicanismo no está siendo utópico sino que está reconociendo que en las democracias modernas los electores necesitan políticos y servidores públicos dotados de virtudes republicanas.

Seguramente, no todos los políticos y servidores públicos responden a esta exigencia política. Pero creo que la tendencia principal va en la dirección que estoy apuntando, porque la democracia incorpora en ella la capacidad de autoperfeccionarse. Los ciudadanos pueden aparecer a veces desinteresados de la política, especialmente en los momentos de calma política, pero en la medida que en que tienen mayor nivel de educación, están mejor informados y, además, saben hasta que punto sus vidas dependen de un buen ejercicio del poder, aprendieron o están aprendiendo cuáles son sus derechos y obligaciones ciudadanas”.

En este camino, el funcionariado debe combinar la actitud responsiva del Estado, con el requisito que se vuelve exigencia del control sobre la gestión pública incrementando sus responsabilidades. Es parte del proceso de hechura de las políticas públicas la necesidad de evaluar las mismas, y de corregirlas, abandonarlas, o darlas por terminadas, relacionando objetivos, metas, y utilización de los recursos disponibles. La responsabilidad en la gestión pública debe ser más que nunca una obligación en el estado democrático moderno, donde se fusionan los principios de soberanía del pueblo y el control de los gobernantes por los gobernados. Si el sentido vertical está dado fundamentalmente en las elecciones, el horizontal no puede menoscabar el contralor 
interorgánico, posibilitando un ejercicio de poder sobrevaluado fácticamente en un poder, en desmedro de los restantes. De ser así las ciencias de las políticas dejarían de cumplir su finalidad y el interés general estaría perdidoso por la acción de los gobernantes. Cabe aclarar entonces, que el control en los períodos eleccionarios es más que un deseo, es más bien una obligación que hace a la salud de la república, la consolidación democráticay la calidad institucional.

El Consejo Científico del CLAD se ha manifestado con notoria solvencia, destacando que la responsabilización (accountability), cuenta con dos formas fundamentales; la responsabilización mediante la introducción de la lógica de resultados en la administración pública y la responsabilización mediante la competencia administrada. Mientras que la primera intenta el control a posteriori de los resultados, la restante trata de adecuar la eficiencia a la responsabilidad en la administración pública. Esto también requiere la participación directa de la ciudadanía en el control e incluso en la implementación de las políticas. "Este fenómeno está ocurriendo en diferentes partes del mundo. Lo que se pone de manifiesto en el concepto de administración pública orientada a los ciudadanos, uno de los aspectos fundamentales de la nueva gestión pública."

La teoría del control asume más de una forma en aras de mejoramiento de la perfomance de la gestión pública, y debe ir de la mano con el aumento de las capacidades institucionales del Estado, legitimando a su vez la acción colectiva impulsada desde el mismo Estado. Podríamos resumir el sistema de controles de la siguiente manera:

1) Control parlamentario. Es parte del principio de la separación de poderes y el sistema de checks and balances, traducido en ocasiones como el control mutuo 


\section{LAS CIENCIAS DE LAS POLÍTICAS Y EL CONTROL COMO REQUISITO NECESARIO DE LA DEMOCRACIA}

entre el Legislativo y el Ejecutivo. Esto amerita evaluar la labor parlamentaria en las nominaciones a cargos públicos, el presupuesto (gestión y ejecución), y el trabajo en comisiones.

2) Controles de procedimiento clásicos. Responde al principio republicano del control interno, a través de las comisiones administrativas de fiscalización del comportamiento financiero y jurídico de los funcionarios. Aquí se admiten los controladores burócratas, y organismos como el Tribunal de Cuentas, el Poder Judicial y las Auditorías generales.

3) El control social. Mas desarrollado contemporáneamente, convierte a los ciudadanos en controladores del poder oficializado. La cogestión en los servicios públicos, la participación en las audiencias públicas, mecanismos de democracia semidirecta, y otras instrumentaciones cuentan con respaldo legal y fáctico.

4) Responsabilidad por la lógica de los resultados. Consiste en la evaluación a posteriori del desempeño de las políticas públicas. Distintos mecanismos se han utilizado para evaluar las políticas, siendo los pioneros los estudios de opinión pública. La revisión incluye fines, metas, la relación entre las demandas del electorado y la satisfacción con los productos volcados desde el subsistema político.

5) Responsabilización por competencia administrada. Tiene su origen en la teoría que subraya que la prestación monopólica de servicios perjudica a la ciudadanía. Su propósito en la implementación es el aumento de proveedores y establecer una competencia administrada entre ellas. Esto lleva a responsabilizar tanto al Estado como a las entidades concesionadas. 
Las ciencias de las políticas y la implementación y evaluación de las políticas públicas, conforman -hasta ahora- la evolución de la política tanto científica como académica, con el aditamento que acorde al pensamiento de Laswell, se ha alcanzado un equilibrio en la pertinencia del objetivo principal de la política y una metodología que se incorpora desde las ciencias sociales en su conjunto. Para obtener conclusiones válidas, también se debe destacar el avance de la política comparada que permite conocer la situación particular de cada Estado, en cada época de estudio, y conciliar una sana competencia analizando el desarrollo de las políticas públicas en diferentes marcos, para comprender y mejorar el desempeño y la responsabilidad en la gestión pública.

Finalmente, el estudio de los factores exógenos y endógenos, permiten una visión mucho más abarcadora, en relación a dos cuestiones esenciales para la virtud republicana. La primera el incrementalismo de la consolidación democrática, segundo la concientización respecto del control y la responsabilización (accountability), tanto por los ciudadanos como por la burocracia misma en busca de la eficiencia.

\section{BIBLIOGRAFÍA INDICATIVA}

Cansino, César, "LA MUERTE DE LA CIENCIA POLITICA", Editorial Sudamericana, Buenos Aires, Argentina, 2008.

CLAD, "LA RESPONSABILIDAD EN LA NUEVA GESTION PUBLICA LATINOAMERICANA”, Brasser Pereira, Luiz Carlos y otros autores, Eudeba, Buenos Aires, Argentina, Septiembre 2000.

Duverger, Maurice, "METODO DE LAS CIENCIAS SOCIALES”, Ariel, Barcelona, España, 1975. 
Easton, David, “ESQUEMA PARA EL ANALISIS POLITICO”, Editorial Amorrortu, Buenos Aires, Argentina, 1969.

García Delgado, Daniel R., “ESTADO Y SOCIEDAD”, FLACSO, Grupo Editorial Norma, Argentina, 1994.

Garner, James W., "INTRODUCTION TO POLITICAL SCIENCE”, American Book Company, New York-Cincinnati-Chicago, E.E.U.U., 1910.

Laswell, Harold, "LA ORIENTACION HACIA LAS POLITICAS", en "EL ESTUDIO DE LAS POLITICAS PUBLICAS”, de Villanueva Aguilar. México, 1996.

Laswell, Harold, "LA CONCEPCION EMERGENTE DE LAS CIENCIAS DE POLITICAS", en "EL ESTUDIO DE LAS POLITICAS PUBLICAS", de Villanueva Aguilar. México, 1996.

Linares Quintana, Segundo V., "SISTEMAS DE PARTIDOS Y SISTEMAS POLITICOS”, Editorial Plus Ultra, Buenos Aires, Argentina, 1976.

Lindblom, Charles, y Dahl Robert, "POLITICA ECONOMIA Y BIENESTAR”, Paidos, Buenos Aires, Argentina, 1971.

O’Donell, Guillermo, “CONTRAPUNTOS”. Ensayos escogidos sobre autoritarismo y democratización. Paidós, Buenos Aires, Argentina, 1997.

Torgerson, Douglas, "EL ANALISIS DE POLITICAS PUBLICAS. ¿LA RESTAURACION DE LA PHRONESIS?, en "LA CIENCIA POLITICA EN LA HISTORIA”, Istmo S.A., Madrid, España, 1999.

Villanueva Aguilar, Luis F., "EL ESTUDIO DE LAS POLITICAS PUBLICAS", México, 1996. 
Zimerman, Héctor J., Aquino Britos Armando, del Barco, Ricardo, “30 AÑOSDE DEMOCRACIA. (Argentina 1983-2013)”, Amerindia Ediciones Correntinas, Corrientes, Argentina, 2014.

Zimerman, Héctor J., "LA INTRODUCCION DEL ANALISIS SISTEMICO A LAS CIENCIAS POLITICAS”, Facultad de Derecho, UNNE, Revista N 11, Corrientes, Argentina, Setiembre de 1998. 